\title{
Effect of verapamil studied by programmed electrical stimulation of the heart in patients with paroxysmal re-entrant supraventricular tachycardia
}

\author{
HEIN J. J. WELLENS ${ }^{1}$, S. L. TAN, FRITS W. H. BÄR ${ }^{1}$, DONALD R. DÜREN, \\ K. I. LIE, AND HENK M. DOHMEN \\ From the University Department of Cardiology, Wilhelmina Gasthuis, Amsterdam, The Netherlands
}

Atrioventricular $(A V)$ conduction, ventriculoatrial $(V A)$ conduction, and the mechanism of tachycardia, were studied by programmed electrical stimulation before and after the administration of verapamil, in 10 patients with paroxysmal re-entrant supraventricular tachycardia. In 7 patients the tachycardia circuit was confined to the $A V$ node. In 3 patients an accessory pathway conducting only in the ventriculoatrial direction was used during tachycardia. When administered intravenously during tachycardia, verapamil terminated the arrhythmia in 9 patients. Verapamil lengthened the effective and the functional refractory period of the $A V$ node and the $A V$ nodal transmission time in all patients in whom this could be studied. As a result of these changes, it was not possible to initiate tachycardia in 3 patients. The width of the zone of atrial premature beats able to initiate tachycardia (the tachycardia zone) narrowed in 5 patients, and increased in 2 patients. In 6 of these 7 patients the tachycardia zone shifted to longer premature beat intervals. Verapamil resulted in slowing of the heart rate during tachycardia. Apart from slowing in heart rate during tachycardia and termination of tachycardia after intravenous verapamil, the 3 patients with an accessory pathway showed no beneficial effect of verapamil on the mechanism of initiation of tachycardia. Five patients were restudied after 2 to 3 weeks of oral administration of verapamil. Though less, effects were similar to those obtained after intravenous administration.

Several authors have reported on the beneficial effect of verapamil in patients suffering from supraventricular tachycardia (Bender et al., 1966; Bender, 1967; Schamroth, 1971; Schamroth et al., 1972; Krikler and Spurrell, 1974; Härtel and Hartikainen, 1976). To study the mechanism of this effect, the drug was given to 10 patients in whom supraventricular tachycardias could reproducibly be initiated and terminated by programmed electrical stimulation of the heart.

\section{Material and methods}

Ten patients were studied (Table 1). All suffered from recurrent attacks of electrocardiographically documented supraventricular tachycardia. During sinus rhythm and tachycardia 9 patients showed a normal QRS, and the other a complete right

'Present address: Department of Cardiology, Annadal Hospital, University of Limburg, Maastricht, The Netherlands.

Received for publication 22 October 1976 bundle-branch block configuration. None of the patients showed electrocardiographic evidence of the Wolff-Parkinson-White syndrome. After obtaining informed consent, 4 catheters were introduced into the femoral veins using the Seldinger technique. Two bipolar catheters were positioned high on the lateral wall of the right atrium. One was used for stimulation, the other for recording an intra-atrial electrogram. A tripolar catheter was placed in the region of the bundle of His to record a His bundle electrogram. The fourth (bipolar) catheter was positioned in the apex of the right ventricle and used for ventricular stimulation.

In five patients a left atrial electrogram was recorded by advancing a fifth catheter into the coronary sinus or (through a patent foramen ovale) into the left atrium.

Using the single test stimulus method during right atrial stimulation, the functional and effective refractory periods of the AV node and the effective refractory period of the atrium were measured, and 
the zone of premature beat intervals resulting in atrial echoes or sustained tachycardia determined. Thereafter, using the single test stimulus method, the right ventricle was paced up to its effective refractory period. The refractory period and VA conduction times were measured. Both atrium and ventricle were paced at rates just above the spontaneous sinus rate.

Using criteria previously described (Wellens and Durrer, 1975), 3 patients (Tables 1 and 2, cases 1 to 3) were found to use an accessory AV pathway in the VA direction during tachycardia. In the remaining patients the tachycardia circuit was confined to the AV node. After these measurements and with the patient in tachycardia verapamil $(10 \mathrm{mg})$ was given directly into the right atrium through one of the catheters over a 4-minute period. Within 10 minutes after completion of the drug infusion the same stimulation programme was repeated using identical basic cycle lengths and test stimulus intervals. In 5 patients the stimulation procedure was repeated 2 to 3 weeks later, after they had taken oral verapamil ( $80 \mathrm{mg} 3$ times daily) in the interim. Care was taken to use the same basic driving rate and to place the stimulating and recording electrodes as nearly as possible in the same positions during the first and second catheterisations to minimise the effect of varied approaches to the $\mathrm{AV}$ node on AV nodal function (Amat et al., 1974; Batsford et al., 1974). All data obtained during the stimulation studies were recorded on tape (Ampex FR 1300) and were directly recorded on an 8channel Elema Mingograf recorder. Leads I, II, III, V1, V6, the intracavitary right atrial lead, a left atrial lead if available, and the His bundle lead were recorded simultaneously. For recording the His bundle electrogram an Elema EMT 12 was used. Statistical analyses were performed using the paired $t$ test.

The effective refractory period of the $\mathrm{AV}$ node was defined as the longest $A_{1}-A_{2}$ interval failing to conduct through the AV node. The functional refractory period of the AV node was defined as the shortest attainable $\mathrm{H}_{1}-\mathrm{H}_{2}$ interval. Since it was not consistently possible to determine which part of the VA conduction pathway became refractory during ventricular pacing, using the single test stimulus method, no values will be given for the effective

Table 1 Effects of verapamil on $A V$ conduction

\begin{tabular}{|c|c|c|c|c|c|c|c|c|c|c|c|c|c|c|c|c|}
\hline $\begin{array}{l}\text { Case } \\
\text { No. }\end{array}$ & Sex & $\begin{array}{l}\text { Age } \\
(y)\end{array}$ & $A c c P$ & $\begin{array}{l}B C L \\
\text { (ms) }\end{array}$ & $\begin{array}{l}\text { AH basi } \\
\text { Before } V\end{array}$ & $\begin{array}{l}\text { (ms) } \\
\text { After V }\end{array}$ & Change & Oral V & $\begin{array}{l}E R P_{\text {AV }} \\
\text { Before } V\end{array}$ & $\begin{array}{l}\mathrm{N} \text { (ms) } \\
\text { After } V\end{array}$ & Change & Oral V & $\begin{array}{l}F R P_{\mathrm{AV}} \\
\text { Before } V\end{array}$ & $\begin{array}{l}\text { (ms) } \\
\text { After } V\end{array}$ & Change & Oral V \\
\hline 1 & $\mathbf{M}$ & 26 & + & 600 & 60 & 90 & +30 & - & $<220$ & 260 & - & - & 400 & 440 & +40 & - \\
\hline 2 & $\mathbf{M}$ & 48 & + & 600 & 80 & 100 & +20 & 100 & $<230$ & $<200$ & - & $<200$ & 360 & 390 & +30 & 360 \\
\hline 3 & $F$ & 64 & + & 500 & 90 & 100 & +10 & - & $<200$ & 240 & - & - & 350 & 370 & +20 & - \\
\hline 4 & $\mathbf{M}$ & 27 & 0 & 600 & 130 & 190 & +60 & 180 & 260 & 430 & 170 & $<290$ & 350 & 380 & +30 & 380 \\
\hline 5 & $\mathbf{M}$ & 59 & 0 & 500 & 110 & 120 & +10 & - & $<210$ & $<230$ & - & - & 340 & 360 & +20 & - \\
\hline 6 & $\mathbf{F}$ & 54 & 0 & 500 & 50 & 60 & +10 & - & 290 & 310 & 20 & - & 350 & 380 & +30 & - \\
\hline 7 & $\mathbf{M}$ & 50 & 0 & 600 & 110 & 120 & +10 & 120 & $<220$ & $<230$ & - & $<220$ & 410 & 430 & +20 & 430 \\
\hline 8 & $\mathbf{M}$ & 56 & 0 & 600 & 70 & 80 & +10 & - & 230 & 340 & 110 & - & 470 & 590 & +120 & - \\
\hline 9 & $\mathbf{F}$ & 47 & 0 & 600 & 90 & 110 & +20 & 120 & $<190$ & 240 & - & $<210$ & 330 & 460 & +130 & 480 \\
\hline 10 & $\mathbf{M}$ & 32 & 0 & 600 & 50 & 70 & +20 & 70 & 210 & 230 & 20 & 240 & 310 & 320 & +10 & 330 \\
\hline
\end{tabular}

Abbreviations: Acc P, accessory pathway; BCL, basic cycle length; AH, atrium-His interval; ERP $\mathbf{A V N}_{\mathrm{N}}$, effective refractory period atrio-

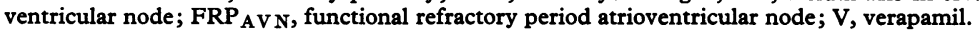

Table 2 Effects of verapamil on initiation and termination of tachycardia

\begin{tabular}{|c|c|c|c|c|c|c|c|c|c|c|c|}
\hline $\begin{array}{l}\text { Case } \\
\text { No. }\end{array}$ & $B C L$ & $\begin{array}{l}\text { Re-entry } z \\
\text { Before } V\end{array}$ & $\begin{array}{l}\text { After } V \\
\text { Aftriu }\end{array}$ & $\begin{array}{l}\text { n) (ms) } \\
\text { Change }\end{array}$ & Oral $V$ & $\begin{array}{l}\text { Tachy } z o \\
\text { Before } V\end{array}$ & $\begin{array}{c}\text { ne (atrium) } \\
\text { After } V\end{array}$ & $\begin{array}{l}\text { (ms) } \\
\text { Change }\end{array}$ & Oral V & $\begin{array}{l}\text { Termination of } \\
\text { tachycardia } \\
\text { with } V\end{array}$ & $\begin{array}{l}\text { Increase in } R R \\
\text { interval during } \\
\text { tachycardia after } V\end{array}$ \\
\hline $\begin{array}{r}1 \\
2 \\
3 \\
4 \\
5 \\
6 \\
7 \\
8 \\
9 \\
10\end{array}$ & $\begin{array}{l}600 \\
600 \\
500 \\
600 \\
500 \\
500 \\
600 \\
600 \\
600 \\
600\end{array}$ & $\begin{array}{l}290-220 \\
280-230 \\
290-200 \\
340-260 \\
250-210 \\
320-290 \\
280-220 \\
270-230 \\
260-190 \\
260-210\end{array}$ & $\begin{array}{l}290-260 \\
260-200 \\
300-240 \\
540-430 \\
- \\
280-230 \\
360-340 \\
- \\
240-230\end{array}$ & $\begin{array}{l}-40 \\
+10 \\
-30 \\
+30 \\
- \\
-10 \\
-20 \\
-40\end{array}$ & $\begin{array}{l}\overline{300-200} \\
\overline{360}-280 \\
- \\
\overline{290} \\
\overline{2} \\
270-210 \\
240-220\end{array}$ & $\begin{array}{l}290-220 \\
280-230 \\
290-200 \\
340-260 \\
250-210 \\
320-290 \\
280-220 \\
270-230 \\
260-190 \\
260-210\end{array}$ & $\begin{array}{l}290-260 \\
260-200 \\
300-240 \\
540-430 \\
- \\
\frac{280-320}{360-340} \\
\frac{240-230}{}\end{array}$ & $\begin{array}{l}-40 \\
+10 \\
-30 \\
+30 \\
- \\
-10 \\
-20 \\
-40\end{array}$ & $\begin{array}{l}- \\
300-200 \\
360-280 \\
- \\
- \\
- \\
-\end{array}$ & $\begin{array}{l}+ \\
+ \\
0 \\
+ \\
+ \\
+ \\
+ \\
+ \\
+ \\
+\end{array}$ & $\begin{array}{l}320 \rightarrow 360 \\
250 \rightarrow 320 \\
360 \rightarrow 400 \\
420 \rightarrow 480 \\
240 \rightarrow 280 \\
260 \rightarrow 280 \\
300 \rightarrow 370 \\
330 \rightarrow 420 \\
360 \rightarrow 450 \\
340 \rightarrow 380\end{array}$ \\
\hline
\end{tabular}


refractory period of the different parts of the pathway. Serum levels of verapamil were not determined during the acute or chronic studies.

\section{Results}

\section{AV CONDUCTION}

The $\mathrm{AH}$ interval, and the effective refractory period (ERP) and functional refractory period (FRP) of the AV node lengthened after verapamil (Table 1). The AH interval increased by $20 \pm 16$ ms $(P<0.001)$; the FRP $_{\mathrm{AvN}}$ by $45 \pm 45 \mathrm{~ms}$ $(\mathrm{P}<0.001)$.

\section{VA CONDUCTION}

All patients showed ventriculoatrial conduction during ventricular pacing. On applying the single test stimulation procedure, 3 patients (cases 1 to 3 ) showed no change in VA conduction time on shortening the $\mathrm{V}_{1}-\mathrm{V}_{2}$ interval up to the refractory period of the ventricle; in 2 (cases 2 and 3 ) the His bundle electrogram was seen to approach the atrial electrogram. In these 3 patients, who all had VA conduction over an accessory pathway, no change in effective refractory period of the VA conduction system was seen after verapamil administration. However, the ability to initiate tachycardia by a single ventricular premature beat at longer premature beat intervals (see below) suggests that verapamil resulted in lengthening of the ERP ${ }_{\mathrm{AvN}}$ in the VA direction. In 4 patients (cases 5, 6, 7, and 8), the increase in VA conduction time on shortening the $V_{1}-V_{2}$ interval was found to be located in the $\mathrm{V}_{2}-\mathrm{H}_{2}$ interval, the $\mathrm{H}_{2}-\mathrm{A}_{2}$ interval remaining constant. None of these patients showed any change in these values after verapamil administration. In the remaining 3 patients (cases 4, 9, and 10) VA conduction time following premature stimuli increased on shortening the $\mathrm{V}_{1}-\mathrm{V}_{2}$ interval; in the absence of a His bundle electrogram the site of increase in $\mathrm{V}_{2}-\mathrm{A}_{2}$ interval could not be determined. In 2 of these patients (cases 4 and 5), apart from lengthening of the VA conduction time, the VA effective refractory period increased after verapamil by, respectively, 30 and $50 \mathrm{~ms}$; case 4 was restudied after oral verapamil administration and showed a $40 \mathrm{~ms}$ increase in effective refractory period of the VA conduction system.

\section{MECHANISM OF TACHYCARDIA}

\section{Atrial stimulation}

As shown in Table 2, tachycardia could be initiated by a single atrial premature beat in all patients before verapamil. In cases 1 to 3 , a gradual increase in $\mathrm{A}_{2}-\mathrm{H}_{2}$ interval was seen with increasing prematurity of the atrial test stimulus, with initiation of tachycardia at a critical $\mathrm{A}_{2}-\mathrm{H}_{2}$ interval. In the other 7 patients (cases 4 to 10 ) a sudden prolongation of the $A_{2}-H_{2}$ interval of $50 \mathrm{~ms}$ or more was seen when the $\mathbf{A}_{2}-\mathrm{H}_{\mathbf{2}}$ interval of the latest premature beat able to initiate tachycardia was compared with the $\mathrm{A}_{2}-\mathrm{H}_{2}$ interval of the premature beat given $10 \mathrm{~ms}$ later. The width of the zone, during which an atrial test stimulus resulted in tachycardia, ranged from 30 to $90 \mathrm{~ms}$. In cases 4 to 10 , atrial activation in the His bundle lead during the first beat of tachycardia preceded or occurred simultaneously with ventricular activation. In cases 1 to 3 , atrial activation occurred after ventricular activation.

In all patients verapamil was injected during tachycardia. They all showed (Table 2) an increase in RR interval with a maximum of $53 \pm 20 \mathrm{~ms}$ $(P<0.001)$. This increase in $R R$ interval during tachycardia was found to be located in the $\mathrm{AH}$ interval only. No effect was noted on the HA interval during tachycardia. In 9 patients verapamil resulted in termination of tachycardia 9 seconds to $2 \frac{1}{2}$ minutes after the end of the injection. Tachycardia always ended with a $P$ wave, suggesting that block occurred in the anterograde limb of the re-entry circuit. In one patient only alternation in $\mathrm{AH}$ interval (by $20 \mathrm{~ms}$ ) was observed before termination of tachycardia (Vohra et al., 1974a). None of our patients showed the emergence of premature beats before reversion of tachycardia (Vohra et al., 1974b).

After intravenous verapamil no tachycardia could be initiated during atrial pacing in 3 patients (Table 2). An example is given in Fig 1,2, and 3. The width of the tachycardia zone increased in 2 of the remaining 7 patients and decreased in 5 . In all except case 2, the earliest atrial premature beat able to initiate tachycardia was later after verapamil because of the increase in length of the ERP $_{\text {AvN }}$.

\section{Ventricular stimulation}

Only in patients with an accessory pathway (cases 1 to 3) was it possible to initiate tachycardia by a single ventricular premature beat during ventricular pacing; the width of the tachycardia zone in these 3 patients measured, respectively, 80,50 , and $90 \mathrm{~ms}$. In all 3, tachycardia could still be initiated after verapamil. In cases 2 and 3 the width of the tachycardia zone increased after verapamil administration by, respectively, 20 and $70 \mathrm{~ms}$, suggesting lengthening of the effective refractory period of the AV node in the VA direction; no change was observed in case 1.

All patients (including cases 1 to 3 ) in whom tachycardia could still be initiated during atrial or ventricular pacing after verapamil showed a slower heart rate during tachycardia. This reduction in 
heart rate made it possible to terminate tachycardia by a single atrial premature beat in those patients where before verapamil two atrial premature beats were required to end tachycardia (Fig. 4).

Chronic oral verapamil administration

As shown in Tables 1 and 2 , in the 5 patients studied, the effect of chronic oral verapamil administration was usually less than that of intravenous administration. However, in 2 patients (cases 7 and 10) tachycardia could not be initiated during oral administration of verapamil while this was still possible after intravenous administration of the drug.
In one patient (case 4) the pattern of sudden increase in $A_{2}-H_{2}$ interval on entering the tachycardia zone present before and after intravenous verapamil (Fig. 5) was no longer present during administration of verapamil (Fig. 6).

\section{Discussion}

Verapamil is an antiarrhythmic drug which received considerable attention because of its ability selectively to block the slow inward current in the isolated preparation (Kohlhardt et al., 1972; Cranefield et al., 1974; Wit and Cranefield, 1974; Zipes, 1975). Since both sinus and AV node

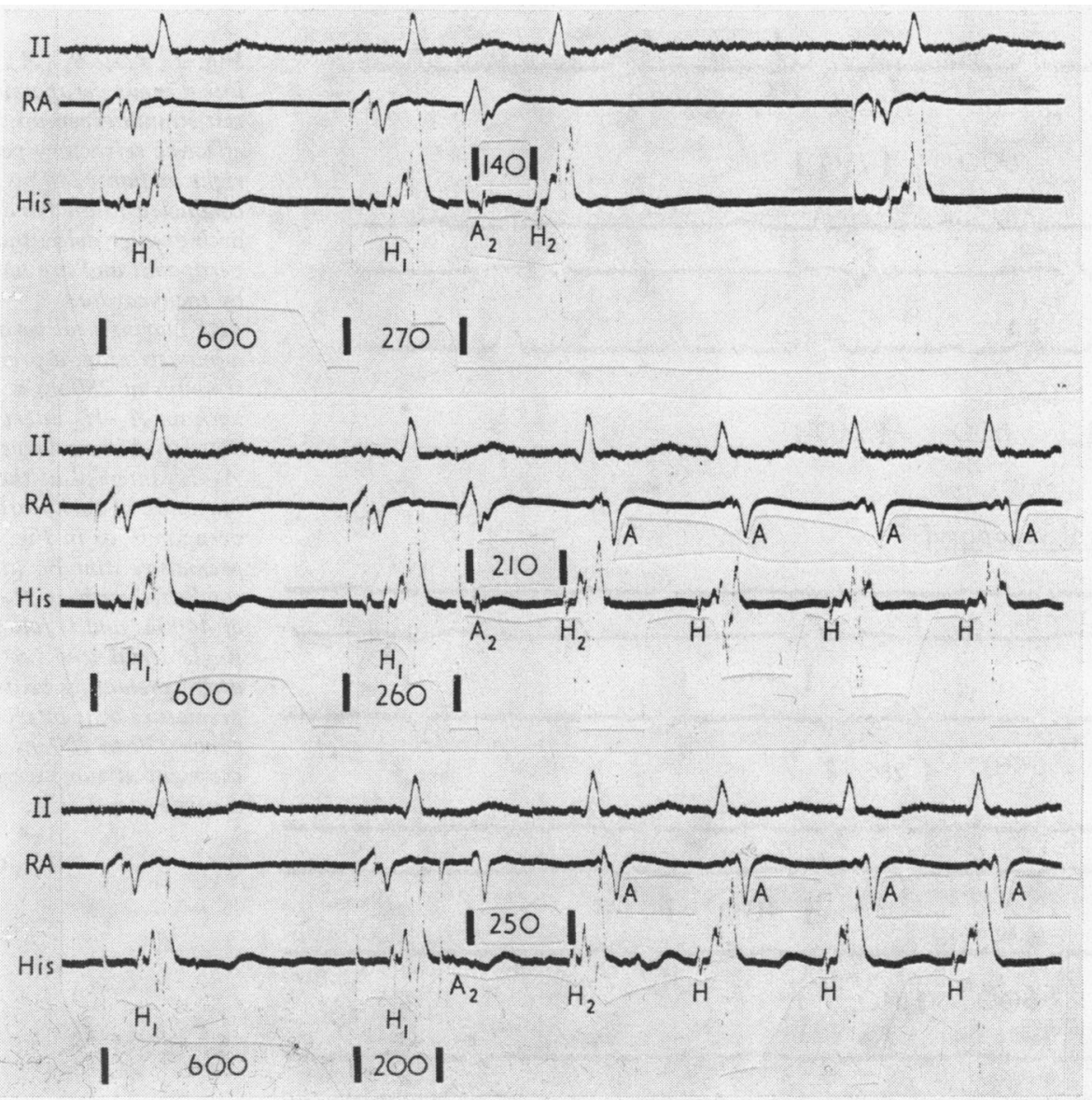

Fig. 1 Case 9. Before verapamil. Initiation of tachycardia by a single atrial premature beat during atrial pacing at a basic cycle length of $600 \mathrm{~ms}$. Three different premature beat intervals are shown. When the interval of the test pulse is changed from 270 to $260 \mathrm{~ms}$, there is an increase in $A_{2}-H_{2}$ interval from $140 \mathrm{~ms}$ to $210 \mathrm{~ms}$. This increase in $\mathrm{A}_{2}-\mathrm{H}_{2}$ interval is followed by tachycardia. Further increase in prematurity of the test pulse resulted in a gradual increase in $\mathrm{A}_{2}-\mathrm{H}_{2}$ interval followed by tachycardia. 
function are thought to be maintained by the operation of a slow channel mechanism, verapamil has been used for the treatment of supraventricular tachycardias. Our observations confirm previous observations on the effectiveness of intravenous verapamil in terminating reciprocal supraventricular tachycardia in man (Schamroth et al., 1972; Krikler and Spurrell, 1974; Härtel and Hartikainen, 1976). In fact, the almost instantaneous effect of intravenous administration has made the drug our first choice of treatment if vagal manoeuvres fail to terminate paroxysmal supraventricular tachycardia.

As has previously been shown by Neuss and Schlepper (1971), Husaini et al. (1973), and Roy et al. (1974), verapamil lengthens the refractory period of the AV node and the transnodal conduction time. We found that both in patients with re-entrant $\mathrm{AV}$ nodal tachycardia and in patients with a concealed AV pathway, termination of

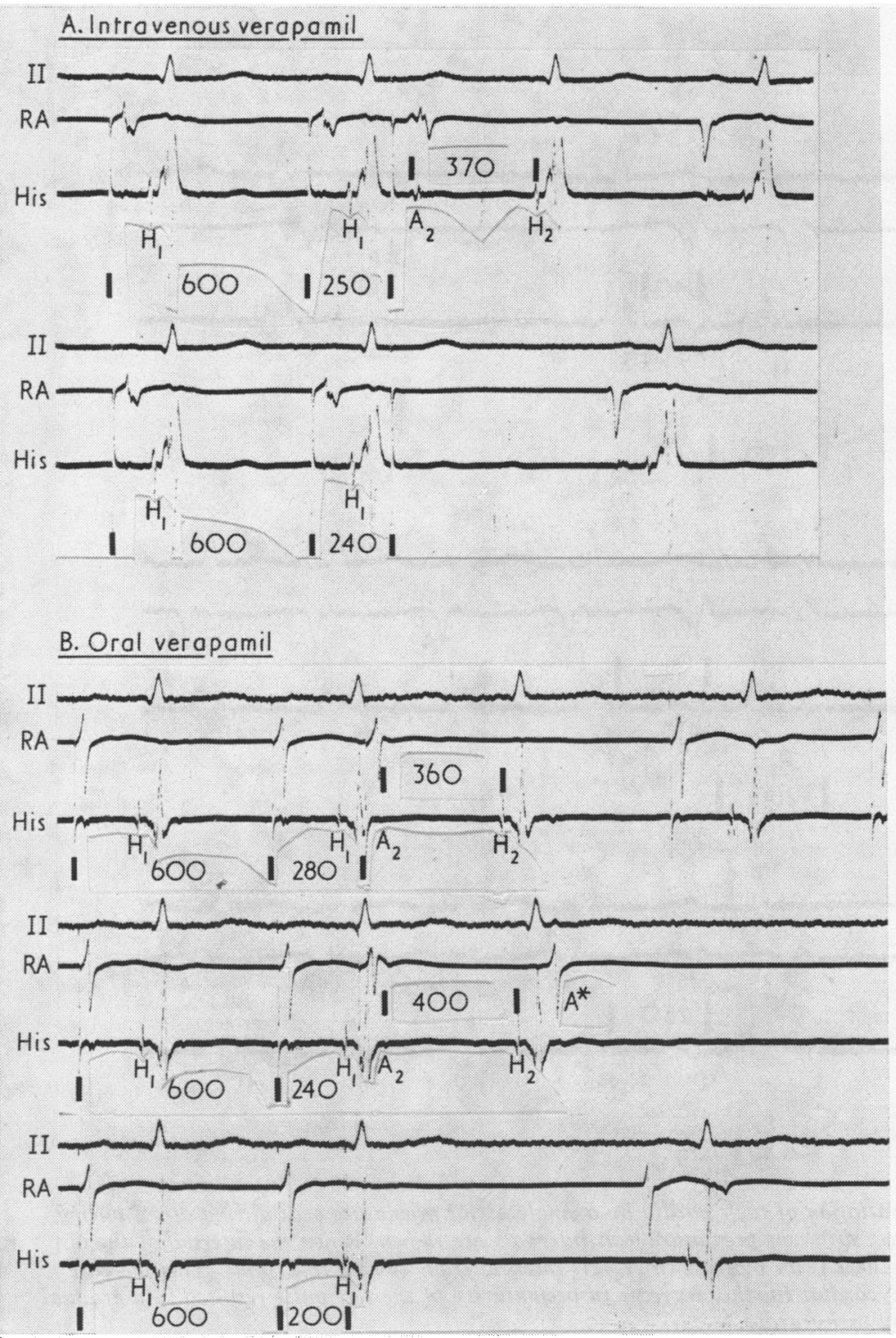

Fig. 2 Case 9. (A) After intravenous verapamil, premature test stimuli given up to the effective refractory period of the right atrium (240 ms) are conducted to the bundle of $\mathrm{His}$ with greater delay than before verapamil and are not followed by tachycardia.

(B) During oral verapamil administration, a premature stimulus at $280 \mathrm{~ms}$ is conducted with an $\mathrm{A}_{2}-\mathrm{H}_{2}$ interval of $360 \mathrm{~ms}(150 \mathrm{~ms}$ longer than the $\mathrm{A}_{2}-\mathrm{H}_{2}$ interval at the time of initiation of tachycardia before verapamil, as in Fig. 1). A premature stimulus at $240 \mathrm{~ms}$ is conducted with an $\mathrm{A}_{2}-\mathrm{H}_{2}$ interval of $400 \mathrm{~ms}$ and is followed by $a$ single atrial echo $\left(A^{\star}\right)$. All atrial premature beats in the premature beat interval $\left(A_{1}-A_{2}\right)$ range 270 to $200 \mathrm{~ms}$ (the ERP of the right atrium) were followed by a single atrial echo. 
tachycardia resulted from block in the anterograde AV nodal limb of the tachycardia circuit. Verapamil did not affect the retrograde pathway in any patient. This effect has previously been reported by Spurrell et al. (1974a) in patients with the WPW syndrome prone to circus movement tachycardia. In the view of the same authors (1974b), the absence of effect of verapamil on the VA limb of the tachycardia circuit implied that VA conduction was by concealed AV nodal bypass. However, we found that verapamil had no effect on the VA limb of the tachycardia circuit in patients fulfilling all the criteria of intranodal re-entry (Wellens and Durrer,

Fig. 3 Case 9. Relation between $A_{1}-A_{2}$ interval and $\rightarrow$ $\mathrm{H}_{1}-\mathrm{H}_{2}$ interval before and after intravenous verapamil, and during oral verapamil administration. Before verapamil premature beats given in the interval range 260 to $190 \mathrm{~ms}$ resulted in tachycardia. The $F_{R P_{A N}}$ before verapamil measured $330 \mathrm{~ms}$. After intravenous verapamil, tachycardias could not be initiated; the FRP $A V N$ increased to $490 \mathrm{~ms}$. After oral verapamil tachycardias could not be initiated. Only single atrial echoes followed premature beats given in the interval range 270 to $200 \mathrm{~ms}$. The FRP $A V N$ measured $470 \mathrm{~ms}$.
1975), including simultaneous activation during tachycardia of atrium and ventricle. In addition, during single test stimulation, an increase in HA interval was seen in only 2 patients. These observations suggest that the absence of effect of verapamil

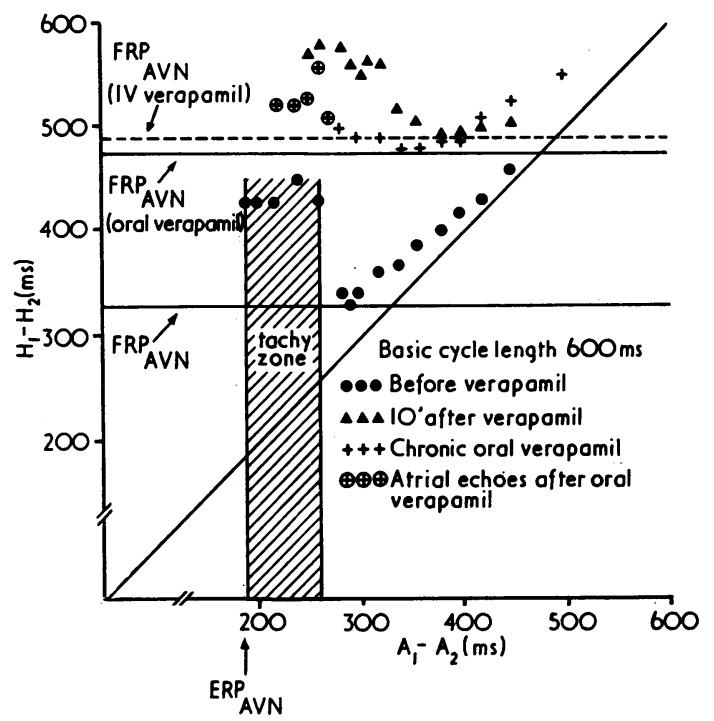

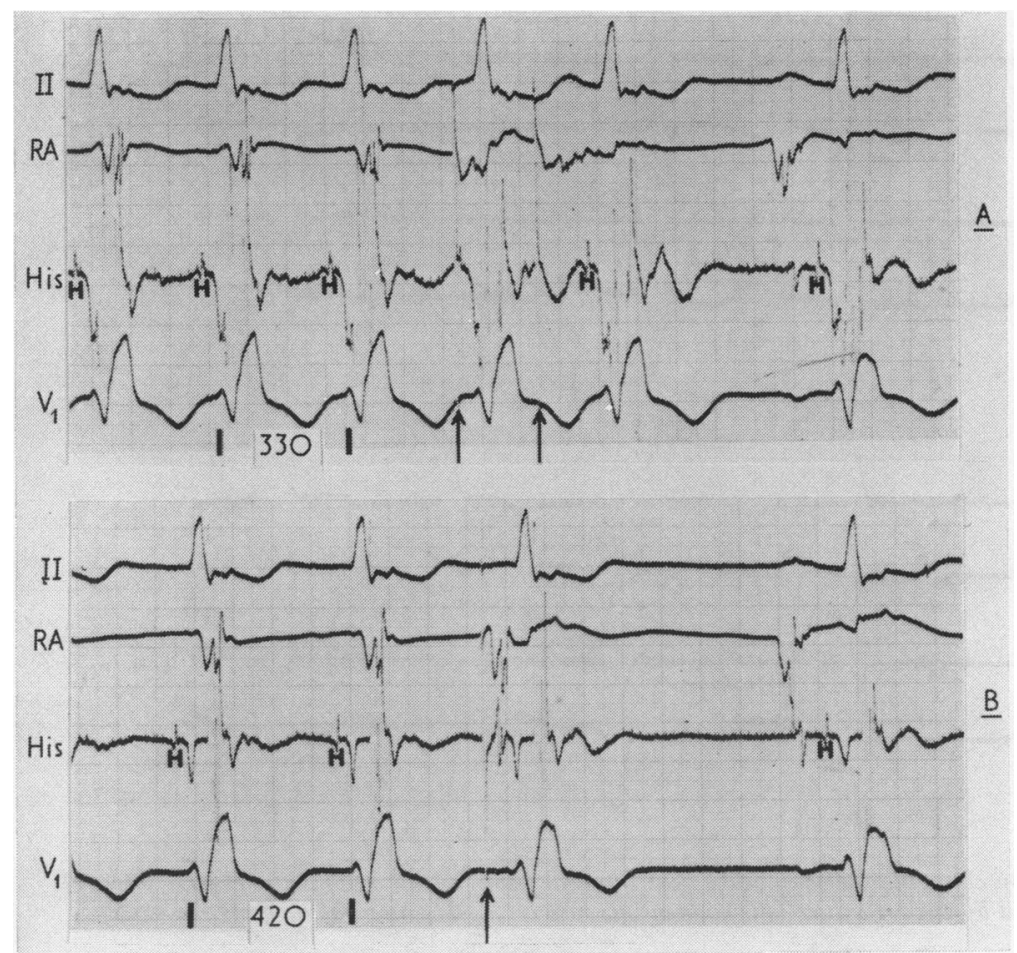

Fig. 4 Case 8. AV nodal tachycardia $(A)$ before and $(B)$ after intravenous verapamil. Note: (1) increase in length of the tachycardia cycle from $330 \mathrm{~ms}$ to $420 \mathrm{~ms}$; (2) localisation of the increase in cycle length in the $A H$ interval; and (3) termination of tachycardia by a single atrial premature beat (single arrow) instead of two ( 2 arrows) because of slowing in rate of tachycardia after verapamil. 
on VA conduction does not prove VA conduction over an AV nodal bypass.

Our data do not confirm the explanation given by Wit and Cranefield (1974) for the effect of verapamil in preventing AV nodal tachycardia. In the rabbit heart they noted that verapamil resulted in such lengthening of the effective refractory period of the node that premature impulses could not enter the node early enough to be slowed sufficiently to initiate re-entry. As seen after digitalis administration (Wellens et al., 1975; Wu et al., 1975), our patients showed slowing in AV nodal transmission with verapamil despite lengthening of the effective refractory period of the node. They all showed maximal $\mathrm{AH}$ intervals which were of the same order as or even longer (Fig. 1 and 2) than those before verapamil. As shown in Fig. 2, it was still often possible to elicit single atrial echo beats after verapamil, as after digitalis. Apparently prolongation of the refractory period of the anterograde AV nodal part of the re-entry circuit prevented the atrial echo from returning to the ventricle and initiating tachycardia. When verapamil was injected during tachycardia, and also if tachycardia could still be initiated after the drug had been given, slowing of transmission through the anterograde AV nodal part of the tachycardia circuit resulted in slowing of the tachycardia. As has been pointed out by Denes et al. (1973) and Wu et al. (1974), this phenomenon of selective slowing of conduction through the AV node makes verapamil, like digitalis and propranolol, a drug that may actually favour initiation and perpetuation of tachycardia if VA conduction occurs over an accessory pathway. By delaying AV nodal conduction these drugs will increase the chance for the impulse to find the ventricular end of the accessory pathway excitable, thereby promoting VA conduction over this pathway and initiation of tachycardia.

In 2 of our patients short $\mathrm{AH}$ intervals were present. As previously described by Both et al. (1975), the effect of verapamil on the effective and functional refractory period of the AV node and AV nodal transmission time was less in these patients than in those with normal $\mathrm{AH}$ intervals. Though small, the increase in these measurements after verapamil suggests an anatomically small $\mathrm{AV}$ node or an intranodal short circuit rather than an AV nodal bypass fibre as the explanation for the short AH time in our 2 patients. Of practical im-

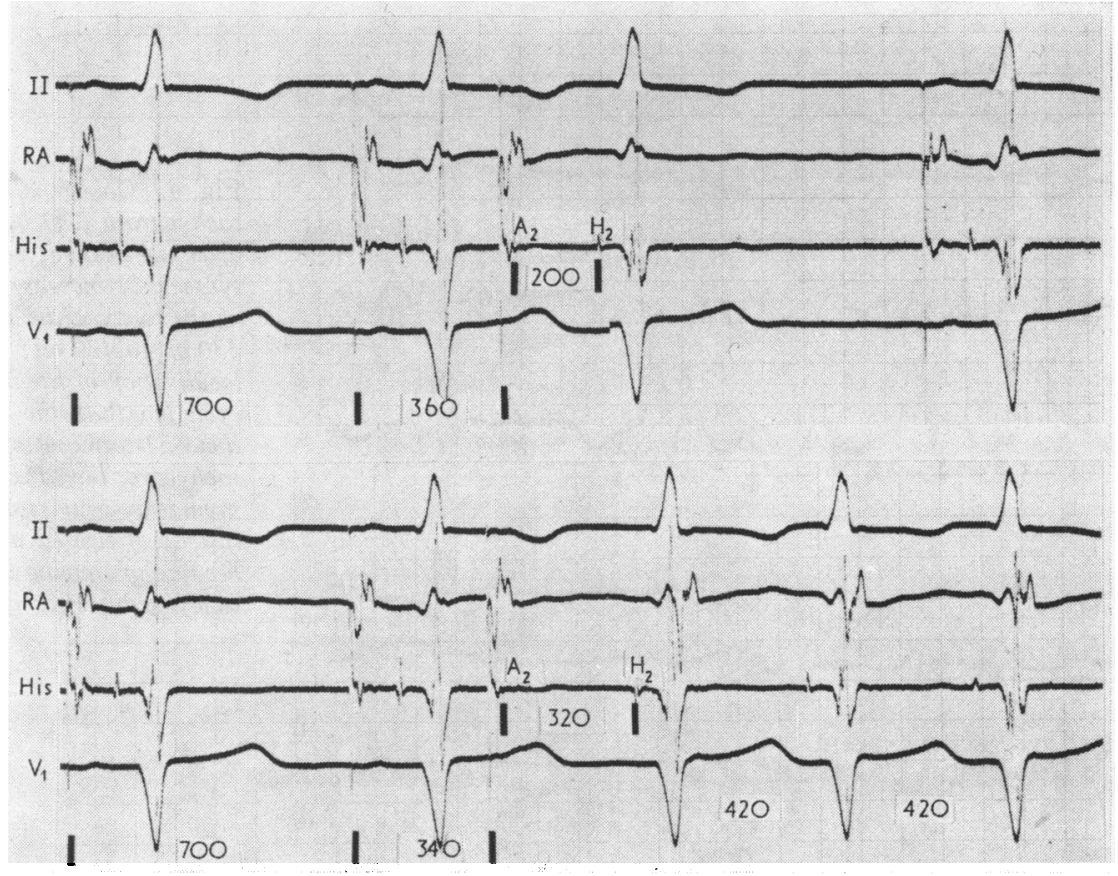

Fig. 5 Case 4. Before verapamil. On changing the premature beat interval from 360 to 340 ms the $A_{2}-H_{2}$ interval increases from 200 to $320 \mathrm{~ms}$, followed by tachycardia. This sudden increase in $A_{2}-H_{2}$ interval suggests the presence of double $A V$ nodal pathways. 
portance was the observation that in both these patients the tachycardia could readily be terminated by verapamil. We have previously reported (Wellens et al., 1975), a change in AV nodal transmission pattern after digitalis from a 'double pathway' curve into a 'smooth' curve (Denes et al., 1973). In one patient (Fig. 5 and 6) in whom a 'double pathway' curve was still present after intravenous verapamil a smooth curve was obtained after chronic oral administration. Possible explanations for this phenomenon have been given elsewhere (Wellens et al., 1975). In the 5 patients restudied after oral administration of verapamil, the same direction of changes (though less in degree) was found when the effects of intravenous and oral administration of the drug were compared. As with digitalis and AV nodal tachycardia (Wellens et al., 1975), this suggests that data obtained after intravenous administration of verapamil can be used for selecting patients likely to benefit from chronic oral verapamil administration.

\section{References}

Amat, F., Denes, P., Wu, D., Pietras, R. J., and Rosen, K. (1974). The effects of atrial pacing site on A-V nodal function (abstract). American fournal of Cardiology, 33, 123.

Batsford, W., Akhtar, M., Caracta, A. R., Josephson, M. E., Seides, S. F., and Damato, A. N. (1974). Effect of atrial stimulation site on the electrophysiological properties of the atrioventricular node in man. Circulation, 50, 283-292.

Bender, F. (1967). Isoptin zur Behandlung der tachykarden Form des Vorhofflatterns. Medizinische Klinik, 62, 634-636.

Bender, F., Kojima, N., Reploh, H. D., and Oelmann, G. (1966). Behandlung tachykarder Rhythmusstörungen des Herzens durch Beta-Rezeptorenblockade des Atrioventrikulargewebes. Medizinische Welt, 1, 1120-1123.

Both, A., Seipel, L., and Loogen, F. (1975). Diagnostische Probleme beim L.G.L. Syndrom. In His-Bündel-Elektrographie, p. 147. Ed. by L. Seipel, F. Loogen, and A. Both. Schattauer Verlag, Stuttgart.

Cranefield, P. F., Aronson, R. S., and Wit, A. L. (1974). Effect of verapamil on the normal action potential and on a calcium-dependent slow response of canine cardiac Purkinje fibers. Circulation Research, 34, 204-213.

Denes, P., Wu. D., Dhingra, R. C., Chuquimia, R., and Rosen, K. (1973). Demonstration of dual A-V nodal path-

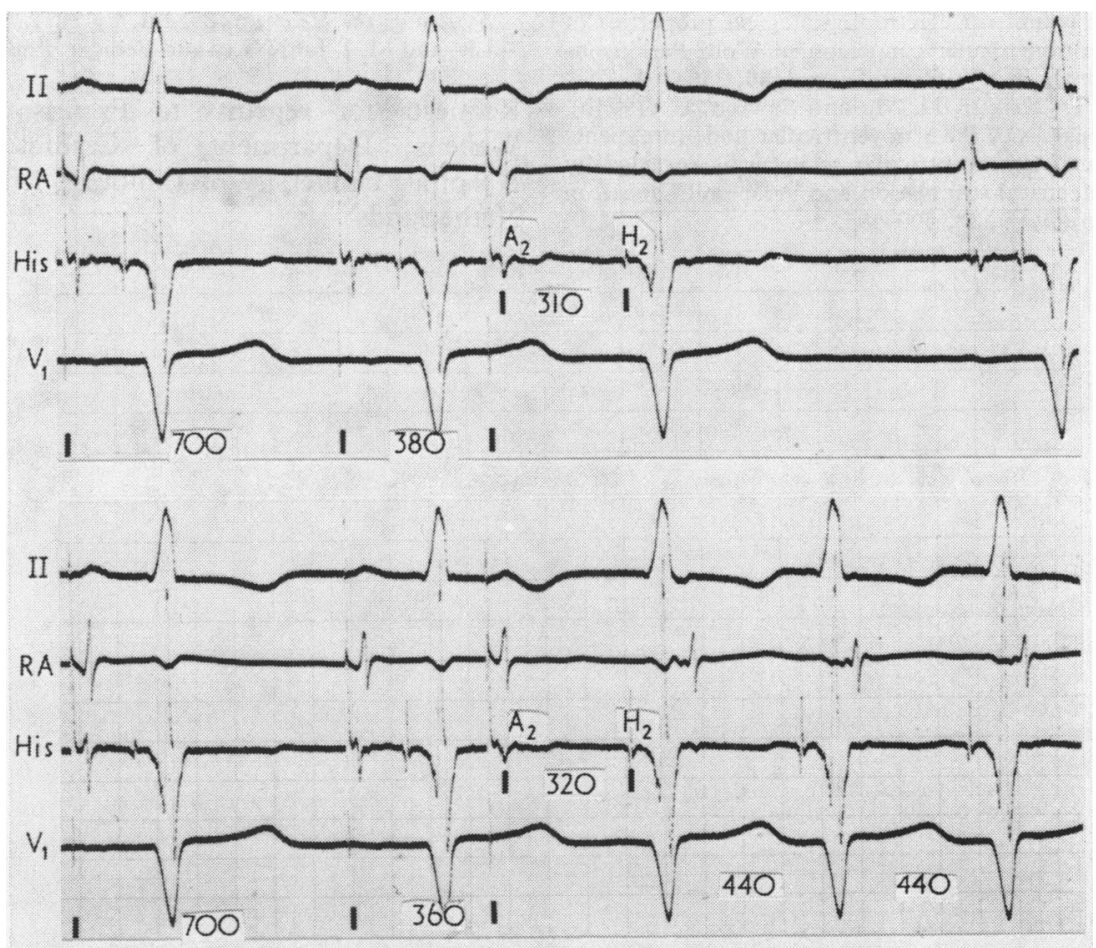

Fig. 6 Case 4. During oral verapamil administration. On changing the premature beat interval from 380 to $360 \mathrm{~ms}$ the $A_{2}-H_{2}$ interval now increases by only $10 \mathrm{~ms}$ (from 310 to $320 \mathrm{~ms}$ ). The latter premature beat is followed by tachycardia. Possible explanations for this phenomenon (change from a 'double pathway' curve into a 'smooth' curve) are given elsewhere (Wellens et al., 1975). 
ways in patients with paroxysmal supraventricular tachycardia. Circulation, 48, 549-555.

Härtel, G., and Hartikainen, M. (1976). Comparison of verapamil and practolol in paroxysmal supraventricular tachycardia. European fournal of Cardiology, 4, 87-90.

Husaini, M. H., Kvasnicka, J., Ryden, L., and Holmberg, S. (1973). Action of verapamil on sinus node, atrioventricular, and intraventricular conduction. British Heart fournal, 35, 734-737.

Kohlhardt, M., Bauer, B., and Krause, H. (1972). Differentiation of the transmembrane $\mathrm{Na}$ and $\mathrm{Ca}$ channels in mammalian cardiac fibres by the use of specific inhibitors. Pflügers Archiv für die gesamte Physiologie, 335, 309-322.

Krikler, D., and Spurrell, R. (1974). Verapamil in the treatment of paroxysmal supraventricular tachycardia. Postgraduate Medical fournal, 50, 447-453.

Neuss, H., and Schlepper, M. (1971). Der Einfluss von Verapamil auf die atrio-ventrikuläre Uberleitung. Lokalisation des Wirkungsortes mit His-Bündel Elektrogrammen. Verhandlungen der Deutschen Gesellschaft für Kreislaufforschung, 37, 433-438.

Roy, P. R., Spurrell, R. A. J., and Sowton, E. (1974). The effect of verapamil on the cardiac conduction system in man. Postgraduate Medical fournal, 50, 270-275.

Schamroth, L. (1971). Immediate effects of intravenous verapamil on atrial fibrillation. Cardiovascular Research, $5,419-424$.

Schamroth, L., Krikler, D. M., and Garrett, C. (1972). Immediate effects of intravenous verapamil in cardiac arrhythmias. British Medical fournal, 1, 660-662.

Spurrell, R. A. J., Krikler, D. M., and Sowton, E. (1974a). Effects of verapamil on electrophysiological properties of anomalous atrioventricular connexion in Wolff-ParkinsonWhite syndrome. British Heart fournal, 36, 256-264.

Spurrell, R. A. J., Krikler, D. M., and Sowton, E. (1974b). Concealed bypasses of the atrioventricular node in patients with paroxysmal supraventricular tachycardia revealed by intracardiac electrical stimulation and verapamil. American fournal of Cardiology, 33, 590-595.
Vohra, J., Hunt, D., Stuckey, J., and Sloman, G. (1974a). Cycle length alternation in supraventricular tachycardia after administration of verapamil. British Heart fournal, 36, 570-576.

Vohra, J., Peter, T., Hunt, D., and Sloman, G. (1974b). Verapamil induced premature beats before reversion of supraventricular tachycardia. British Heart fournal, 36, 1186-1193.

Wellens, H. J. J., and Durrer, D. (1975). The role of an accessory atrioventricular pathway in reciprocoal tachycardia. Observations in patients with and without the Wolff-Parkinson-White syndrome. Circulation, 52, 58-72.

Wellens, H. J. J., Düren, D. R., Liem, K. L., and Lie, K. I. (1975). Effect of digitalis in patients with paroxysmal atrioventricular nodal tachycardia. Circulation, 52, 779-788.

Wit, A. L., and Cranefield, P. F. (1974). Effect of verapamil on the sinoatrial and atrioventricular nodes of the rabbit and the mechanism by which it arrests re-entrant atrioventricular nodal tachycardia. Circulation Research, 35, 413-425.

Wu, D., Denes, P., Dhingra, R., Khan, A., and Rosen, K. (1974). The effects of propranolol on induction of A-V nodal re-entrant paroxysmal tachycardia. Circulation, 50, 665-677.

Wu, D., Wyndham, C., Amat-Y-Leon, F., Denes, P., Dhingra, R. C., and Rosen, K. (1975). The effects of ouabain on induction of atrioventricular nodal re-entrant paroxysmal supraventricular tachycardia. Circulation, 52, 201-207.

Zipes, D. P. (1975). Recent observations supporting the role of slow current in cardiac electrophysiology. In The Conduction System of the Heart, p. 85. Ed. by H. J. J. Wellens, K. I. Lie, and M. J. Janse. Lea and Febiger, Philadelphia.

Requests for reprints to Professor Hein J. J. Wellens, Department of Cardiology, Annadal Hospital, University of Limburg, Maastricht, The Netherlands. 